\title{
Public Personnel Reforms and Public Sector HRM in Europe
}

\author{
Peter Leisink and Eva Knies
}

\begin{abstract}
This review of the literature on public personnel reforms and public sector HRM concentrates on three major topics. First, studies show that NPM continues to influence public personnel policies across Europe, not so much by a further decentralization and increase in managerial autonomy regarding HR decision-making, but by a partial reorientation of the public service ethic. Second, studies provide evidence that leadership matters for the implementation of public management reforms and the improvement of public service performance. Research shows that HRM can help develop effective leadership. Third, studies have shown that HRM can contribute to a public service motivated workforce. However, recent studies also highlight that the relationship between PSM and performance is complex and contingent, and that there is also a dark side to PSM.
\end{abstract}

\subsection{INTRODUCTION}

This chapter will examine how public sector personnel policies in Europe have been reformed as part of ongoing public management reforms. Multiple austerities related to economic, demographic, and ecological changes (Lodge and Hood 2012) have given a new impetus to such reforms aimed

P. Leisink $(\bowtie) \cdot$ E. Knies

Utrecht University School of Governance, Utrecht, Netherlands

e-mail: p.l.m.leisink@uu.nl

E. Knies

e-mail: e.knies@uu.nl

(C) The Author(s) 2018

E. Ongaro and S. van Thiel (eds.), The Palgrave Handbook of Public

Administration and Management in Europe, https://doi.org/10.1057/978-1-137-55269-3_12 
at increasing efficiency and public service performance. This chapter will also review new issues that have emerged in public sector HRM.

The conceptual context informing this review of research of public personnel reforms and public sector HRM in Europe is reflected by the subsequent research programmes of the permanent Study Group 'Public Personnel Policies' of the European Group for Public Administration (EGPA) over the past 10-15 years (Andersen et al., forthcoming). The main foci of interest throughout the years have been chosen as topics for this review. Two criteria have been used for establishing these topics. First, they served as a 3-year research programme of the Study Group and have continued to direct European research. Second, at least one special issue of an international journal was published to showcase the results of joint European research on that topic next to individual publications. Consequently, the following sections will concentrate on: (1) public personnel reforms, changes in the public service ethic, and public servants' identities; (2) leadership, organizational change, and organizational performance; and (3) HRM, public service motivation (PSM) and public service performance.

\subsection{Public Personnel Reforms, Changes in the Public Service Ethic, and Public Servants' Identities}

A symposium of the International Journal of Public Sector Management (Horton 2006) shows that the interest of European researchers in the field of public personnel policies has not been restricted to changes in personnel management as part of public management reforms, but also included changes in the culture, the value and belief systems of public organizations, and the identities of public servants. Related to the former interest this chapter will address the question as to what extent public personnel policies have changed towards private sector personnel policies. Such a change might be indicated by a growing emphasis on private sector characteristics such as the decentralization of decision-making authority, flexibility, and the display of a more rationalist performance orientation (see Boyne et al. 1999). The broadening of the research agenda is reflected by studies taking an interest in the question whether the adoption of a private sector management logic has resulted in a reorientation of the public service ethic and the role identity of public servants.

\subsubsection{Private Sector-Like Public Personnel Policies?}

Managerial autonomy, which is a key issue in the NPM logic, does not seem to have increased further compared with Ingraham's (2005) assessment of two decades of reforms in HRM. Meyer and Hammerschmid's (2010) study of the degree of decentralization of HR decision-making in central government across the 27 EU Member States shows that overall HR decision-making is still highly centralized. They also show that decentralization, to the extent that this has occurred, does not mean a higher degree of autonomy for individual managers because other actors like employee representatives are typically involved in the decision-making. This finding needs to be qualified in two 
respects. First, there is considerable variation in the extent of centralization between HR practices. Some HR practices are typically decided at central level, such as salaries, codes of conduct and ethical standards, head count reduction, and basic working time arrangements. However, other HR practices tend to be decided at lower hierarchical levels, such as performance-related pay, performance management, training and development, and flexible working time patterns. Secondly, there are considerable differences between countries. Distinguishing between Anglo-Saxon, Continental, Scandinavian, Southern and Eastern European Member States, Meyer and Hammerschmid (2010) find that $\mathrm{HR}$ decision-making ranges from most centralized in Eastern European Countries to less centralized in Anglo-Saxon and Scandinavian EU Member States, with Southern European and Continental Member States occupying a position in between. However, Anglo-Saxon and Scandinavian countries do not differ significantly from Continental EU Member States regarding collective decision-making, i.e. the involvement of other actors, while Southern and Eastern European Member States feature less involvement of multiple actors. Overall, the administrative tradition, represented by these five clusters of countries, is the most important variable explaining the differences in the degree of centralization and collective decision-making in HR practices.

Meyer and Hammerschmid (2010) observe that their study does not allow them to draw conclusions about changes in HR decision-making over time. However, it does not seem very likely that a trend towards further decentralization has occurred. Following the financial crisis in 2008, most European Member States pursued austerity policies for a number of consecutive years. Several comparative empirical studies (Bach and Bordogna 2013; Leisink and Bach 2014) show that wage freezes were the result of unilaterally imposed central government decision-making in for instance France, Italy, Hungary, the Netherlands, and the UK. Given the factual context prevalent across many European countries, a recentralization rather than a decentralization is likely to have occurred.

\subsubsection{Reorientation of the Public Service Ethic and the Role Identity of Public Servants}

The institutional environment of public organizations is characterized by the prevalence of values that shape-and interact with - the identity, beliefs, and actions of public servants. In the Weberian government bureaucracy a public service ethos or a legalistic-bureaucratic logic prevailed (Horton 2006). Its central values that acted as a framework for public servants included legality, neutrality, equity, loyalty, and a service to the public interest. The public employment system involved regulations regarded as a necessary condition to guarantee that public servants acted in accordance with these values, including life-time tenure, merit-based and closed recruitment, and promotion based on seniority. This traditional bureaucratic logic was challenged by NPM ideas that went along with a managerial ideology emphasizing values such as performance, effectiveness, efficiency, and managerial autonomy-instead of detailed personnel regulations - in order to manage, incentivize, evaluate, and 
reward employee performance. Public management scholars (e.g. Van der Wal et al. 2008; Van Thiel et al. 2007) have used these logics as heuristic tools to examine shifts in values and practices of public officials. We review some studies that connect the institutional with the personnel policy perspective.

Meyer and Hammerschmid (2006) examined chief executives of public organizations in Austria-which is a prime example of the bureaucratic 'Rechtsstaat' type of public administration - and found no strong evidence of a takeover of a new managerial orientation. The majority of chief executives continued to regard themselves as servants of the state and referred to the traditional bureaucratic-legalistic logic while a minority developed some kind of hybrid identity. Both subscribe to the necessity of administrative reform and the use of new steering instruments, but at an instrumental level rather than as a result of their adoption of another institutional logic. Both also demand more autonomy, especially with regard to personnel policies which allow too little flexibility. Emery et al. (2014) examined senior civil servants at the federal level in Switzerland, where NPM has enjoyed fertile ground since the 1990s. They conclude that a slow transformation is taking place towards increasing managerialization. This is indicated by the shift in senior civil servants' academic background (from predominantly legal to increasingly business and economics sciences) and the increasing mobility at senior level between the public and private sectors.

Other studies examine public servants generally. Berg (2006) studied managers and employees in three major public services (employment service, social security service, inland revenue) in Norway, which changed from a classical bureaucracy to a more market-based bureaucracy. She found that, apart from top-management, the large majority of employees were critical of the reforms' effects on their ability to do a good job. Although recently recruited managers expressed more enthusiasm about the reforms, Berg $(2006,565)$ points out that this does not necessarily point towards a managerialist identity. Jeannot's (2006) study of employees in French public utilities, which adopted NPM-oriented performance management, also finds that the reactions to the reforms are complex, varied, and contingent. Many employees remain committed to the principles of public service and ignore rules and targets based upon the managerialist logic. Rondeaux' (2014) study of NPM-like reforms in Belgian government demonstrate the contingent relationships between public employees' own identification and their perceptions of the institutionalized organizational identity. Rondeaux (2014) distinguishes three different identity rationales: public service, based on principles and values associated with the Weberian administration; public managerialism, based on principles and values related to NPM; and pragmatism focused more on tangible outputs and outcomes than on principles and values as such. She shows that among Walloon regional government employees pragmatists prevail with many feeling that the reforms have not led to the expected changes. A substantial proportion of employees subscribe to public managerialism, emphasizing performance. A smaller number are not in favour of the reforms, but their views are not explicitly related to the public service identity. Rondeaux (2014) concludes that these results support the hypothesis of identity hybridization. 
Recognizing the diversity of the studies conducted, their results support the conclusion that NPM-related ideas continue to influence public personnel policies across Europe. First, through the partial decentralization of decision-making authority regarding personnel policies. Secondly, the impact of NPM-related personnel management reforms can also be observed in relation to the public service identity and values orientating the work of public employees. There is no full transition from the traditional public service ethic to a managerialist logic. A hybrid logic emerges combining public service values with an orientation on public service performance and citizens/clients. Indeed, executives adhering to a legalistic-bureaucratic orientation do not differ per se from those subscribing to a managerial logic in their public service motivation, at least in continental Europe (Meyer et al. 2014). Public servants' actual behaviours and their self-identity are loosely coupled: there are public servants subscribing to the traditional public service identity who refuse or circumvent working to managerialist rules (Jeannot 2006) while others work with them pragmatically without a related change in their own self-understanding (Meyer and Hammerschmid 2006; Rondeaux 2014).

\subsection{Leadership, Organizational Change and Public Service Performance}

The ongoing public management reforms and the renewed interest in improving public service performance raise interest in the role of managers/leaders in managing organizational change and improving performance. In this section, we will discuss the role of public managers which, in line with general HRM research, has been recognized as of prime importance for the effective implementation of HR policies. Also, we will discuss the impact of management development programmes and discretionary room on managerial performance.

The fundamental debate underlying these questions is whether management can potentially have a significant impact on change and performance. There are two schools of thought: the 'constraints school', advocating that management can only have very limited impact as a result of contextual constraints, and the 'leadership school', which argues that management has sufficient discretion to make a difference (Pettigrew 2013). In this section we will address both sides. On the one hand, we will provide evidence that management can have a significant impact on organizational change and performance. On the other hand, we will address the organizational context which can hinder or promote the potential impact of management.

\subsubsection{Leadership and Organizational Change}

The impact of leadership on organizational change is a topical issue, given continued change as a result of public management reforms, and given the common idea that public sector employees generally have a tendency to resist change as a result of institutional processes (Ritz et al. 2012, 163). 
Building on Leader-Member Exchange (LMX) theory (a relationshipbased approach to leadership), Ritz et al. (2012) studied the effect of leadership on employees' commitment to change. The argument underlying their conceptual model is that a good relationship between employees and their supervisors, indicated by high levels of trust, liking, and obligation, will increase employees' commitment to change. The results of their study in UK local government provided support for their hypothesis that the quality of the manager-employee relationship is important for stimulating commitment to change, especially when employees have low levels of core self-evaluations. In the discussion, Ritz et al. highlight that future studies can further unravel the impact of the public sector context (such as legal constraints and HRM policies) on leadership and its impact on commitment to change. In terms of leadership development, Ritz et al. comment that line managers should be coached to build long-term trust-based relationships with their employees. Given the fact that many managerial roles are fulfilled by functional specialists, rather than people managers, management development is of particular importance in a public sector context.

Van der Voet et al. (2014) also studied the role of leadership in managing organizational change, in particular, change in the values of the organization (see for example Meyer and Hammerschmid 2006). In their study, Van der Voet et al. (2014) included both planned and emergent change, and focused on leaders in formal leadership positions as well as 'informal' leaders. One of their main findings is that changes are implemented most effectively when existing values are carefully reinterpreted and reframed, rather than when old values are simply replaced by new ones. Leadership activities play a crucial role in managing this process. In case of a planned change, important leadership activities include: communicating the change, being a role model, and appointing 'culture champions'. When managing an emergent change, the leadership role is distributed over a larger number of individuals (shared or distributed leadership), and as such managing an emergent change is a more collective effort, which requires: communicating the change, highlighting role models, and institutionalizing the new leadership model.

Overall, these studies show that leadership can have an impact on organizational change, but only when managers are able to build a relationship with their employees and display sufficient leadership skills. Which leadership skills and activities are required to effectively manage change depends on the type of change (planned or emergent, changes in organizational structures or values, etc.) that is intended.

\subsubsection{Leadership and Organizational Performance}

The relationship between leadership and performance has gained increasing attention from public administration and public management scholars. In this section, we will discuss two papers that were published in a special issue 
about leadership in Review of Public Personnel Administration (Vandenabeele et al. 2014), as well as two other European studies which are innovative in terms of their methodology. The studies by Vermeeren et al. (2014), Ritz et al. (2014), published in the RoPPA special issue, represent a larger body of research which studies the effect of leadership style (mostly transformational leadership) on several individual, unit, and organizational level outcomes, such as organizational citizenship behaviour, in-role behaviour, and unit or organizational performance. These studies have in common that they include a wide array of variables which are assumed to mediate the leadership-performance relationship. An often voiced critique is that most of these studies are cross-sectional in nature and rely on single source data. The studies by Jacobsen and Andersen (2015), Bellé (2013) address these limitations by using innovative methodologies.

Vermeeren et al. (2014) studied the relationship between leadership, Human Resource Management, and organizational performance using data collected from Dutch municipal employees. The assumption underlying their study is that by effectively managing frontline employees through the implementation of $\mathrm{HR}$ practices, organizational performance (e.g. the delivery of public services) will improve. Vermeeren et al. suggest that the extent to which line managers implement the organizational HR practices effectively is dependent on their leadership style. More specifically, they assume that a stimulating leadership style (which parallels transformational leadership) will have a positive effect on the number of implemented HR practices, whereas a correcting leadership style (which corresponds with transactional leadership) will have a negative effect. They conclude that the implementation of HR practices has a significant effect on organizational performance, and that this relationship is partly mediated by job satisfaction. A stimulating leadership style has a positive effect on the implementation of HR practices, whereas a correcting leadership style has no significant effect. This implies that leaders are important for managing organizational performance, through their leadership style, as well as through their implementation of HR practices.

Ritz et al. (2014) also studied the relationship between leadership and outcomes, in particular, the effect of transformational leadership on organizational citizenship behaviour (OCB), as an important outcome variable reflecting contextual public performance. Their argument that transformational leadership and OCB are related is based on the notion that transformational leadership inspires followers to change their values, attitudes, and behaviours, and as a result 'go the extra mile' to contribute to the organization's mission. As they argue that public service values are crucial in the context of public organizations, they include public service motivation (PSM) and organizational goal clarification as mediating variables. Based on data collected from municipal employees in Switzerland, the authors conclude that transformational leadership has a significant indirect effect on employees' OCB through PSM and goal clarification. The direct effect of 
transformational leadership on OCB is non-significant. This parallels the finding by Vermeeren et al. that leadership matters for outcomes, although the studies used a slightly different definition of transformational/stimulating leadership and included different mediating variables.

A study of the leadership-performance relationship, which is innovative in terms of its methodology, has been conducted by Jacobsen and Andersen (2015). In a study in Danish schools, using data from teachers and school principals, they tested the hypothesis that employees' perceptions of leadership are stronger correlated with performance, compared to leader-intended leadership. As expected, they found that employees' perceptions of both transactional and transformational leadership are significantly related to objective measures of performance (school added value), whereas leader-intended leadership is not significantly related to performance. Moreover, they showed that leader-intended and employee-perceived leadership are significantly, but weakly related. This study is an important contribution to the literature, as Jacobsen and Andersen use multiple raters in the same study, and they use objective performance data. This is a significant step forward compared to many previous studies, which rely on single source data.

Another innovative European study on this topic of leadership and performance, which made a significant contribution to the field by using an experimental design is the one by Bellé (2013). Using a sample of hospital nurses, who were randomly assigned to a group exposed to transformational leadership and a control group, Bellé showed that leadership had a significant effect on performance (i.e. the number of surgical kits that each nurse had assembled). However, the difference between the experimental and the control group is rather small. Bellé also showed that the effects of transformational leadership were stronger for those nurses that were also exposed to beneficiary contract or self-persuasion interventions.

Overall, these studies provide evidence for the assumption that leadership can (indirectly) contribute to improving public service performance. This is in line with the 'leadership school', which argues that management has sufficient discretion to make a difference (Pettigrew 2013) for performance. However, the studies by Jacobsen and Andersen and Bellé highlight the importance of paying sufficient attention to research design and methods in future studies to provide more robust evidence for the causal relationship between leadership and performance.

\subsubsection{Management/Leadership Development}

The potential impact of leadership on organizational change and organizational performance raises the question what organizations can do to stimulate and facilitate leadership in a public sector context. In other words, what are antecedents of effective public sector leadership? In this section, we will focus on two factors that are found to affect leadership in the public sector and which 
can be initiated or stimulated by the organization (Knies and Leisink 2014): the improvement of leadership knowledge, skills, and abilities through management and leadership development programmes, and the provision of sufficient room for managerial discretion.

Related to the first factor, the improvement of leadership knowledge, skills, and abilities through management and leadership development programmes, McGurk $(2009,2010)$ has contributed to the literature by studying the effect of management and leadership development on organizational change and individual and organizational performance. His study of several public service organizations highlights the relevance of a contextualized approach to management and leadership development. McGurk (2009) reports two case studies and found that in one case the training programme was implemented to achieve regulatory compliance. In this organization, a fire brigade in England, the management and leadership activities (aimed at people management, performance management, and problem-solving), were not applied in the workplace, and as a result had very little effect on managerial performance and organizational outcomes. Although the formal development programme had very little effect, informal learning was an important source for developing leadership skills. In the other case, a train operating company in England, the middle managers were trained to effectively enforce Human Resource policies. These activities did contribute to the successful implementation of the organizational strategy. However, this top-down approach achieved no more than top-down change. In a 2010 case study, conducted in a local authority adult social services department in the UK, McGurk found similar results: traditional management development programmes lead to effective compliance with top-down determined objectives, and have little or no impact on strategic change. On the other hand, a collective and emergent approach to leadership development had a significant impact on strategic change, although not always in the expected direction. Based on his findings, McGurk highlights the importance of a contextualized approach to management and leadership development, arguing that 'off-the-shelf' activities have limitations and that organizations should adapt development programmes to the needs of the professionals and the organization to generate effects. Also, the opportunities for learning transfer need to be considered, for example through the level of middle managers' discretion.

McGurk points to managers' discretionary room as an important determinant of leadership. This is a central issue in a study by Knies and Leisink (2014), who studied leadership and its antecedents in the police force and an academic medical centre. They showed that the leadership behaviour enacted by middle managers is dependent on the level of perceived discretionary room, and that this relationship is mediated through managers' willingness to support their employees. That is, managers who perceive more discretionary room are more willing to support their employees and as a result score more positively on leadership. Additionally, Knies and Leisink showed that 
managers' abilities are another important antecedent of leadership behaviour, which supports the findings by McGurk.

These studies show that the extent to which managers enact leadership is dependent on several individual and contextual factors, and that these factors can, at least partly, be influenced by the organization. This implies that by supporting, developing, and facilitating managerial development and discretion, organizations can improve leadership performance, and ultimately organizational performance.

\subsection{HRM, PSM, and Public Service Performance}

Public personnel policies were traditionally orientated on serving employee well-being. The shift to public sector HRM involves a stronger focus on contributing to public service performance (Boyne et al. 1999). Although employees remain an important stakeholder for whom HRM aims to generate meaningful outcomes, public sector HRM is also intent on contributing to outcomes that are relevant for other stakeholders such as clients and society. European researchers take a strong interest in the role PSM can have in HRM as a resource for public service performance. This is based on the assumption that HR practices and public managers' leadership behaviour can have a positive effect on employees' PSM, their willingness to exert extra effort, and ultimately on individual and organizational performance. This section first examines studies that investigated to what extent HRM and managers' leadership behaviour can influence employees' PSM, and then to what extent and how PSM is related to employee and organizational outcomes.

\subsubsection{HRM Influence on Employees' PSM}

The interest in PSM as a potential resource for public service goes back to the seminal article by Perry and Wise (1990). They expressed concern over the decline in public trust in government which they related to the rise of public choice and the growing popularity of monetary incentive systems. Contrary to these trends, Perry and Wise proposed the view that public service motives energize and direct the behaviour of public employees. Subsequent research has provided insight into the ways in which personnel policies affect employees' PSM.

The idea that HRM can contribute to public organizations' performance by attracting public service motivated employees (Leisink and Steijn 2008) was supported by studies pointing out how human resource professionals could tap PSM and related concepts such as mission valence and personorganization fit with a view to recruit prospective employees (Kjeldsen and Jacobsen 2013; Waldner 2012). The other idea that public managers' actions can increase-or decrease-employees' PSM was less self-evident because that idea presupposes that PSM is not a stable trait. By now research of the 
very nature of PSM (Vogel and Kroll 2015) as well as studies of the potential effects of specific personnel practices on PSM have shown that PSM can be affected over time although it is more stable than employee attitudes such as job satisfaction.

Thus there is evidence that organizations can attain a public service motivated workforce not only by attracting public service motivated employees, but also by strengthening their PSM through training programmes, discussing cases and clients with colleagues and supervisors (Kjeldsen 2013), and by supervisors' transformational leadership (Vandenabeele 2014). On the other hand, personnel policies can also affect their employees' PSM negatively. Weibel et al. (2010) show that performance-related pay sometimes decreases employees' personal efforts because pay-for-performance has a strong crowding out effect on intrinsic motivation which is the main motive in interesting tasks that prevailed in the public sector. A study by Jacobsen et al. (2014) extends the previous study of the crowding out effect of financial incentives by including the pivotal role of employees' perception of managerial actions. They show that an external intervention in Danish schools- the introduction of obligatory student plans-crowds out school teachers' PSM when their manager's action is perceived as controlling.

\subsubsection{HRM, PSM and Performance}

The mixed results of early US studies inspired European researchers to go beyond merely examining the PSM-performance relationship by adding variables related to personnel policies such as such as person-environment fit, organizational commitment, and leadership.

A 2009 special issue of the International Review of Administrative Sciences on PSM and performance presents several examples of European contributions to knowledge of the PSM-performance relationship. Vandenabeele (2009) showed that Flemish public service motivated civil servants exhibited higher levels of individual performance and that this relationship was mediated completely or partially by job satisfaction and employees' affective and normative organizational commitment. Leisink and Steijn (2009) surveyed public sector employees in the Netherlands and found a positive relationship between their PSM and their job performance but also that a PSM-job fit had an independent direct effect on their job performance. Andersen (2009) also studied individual job performance, in her case of health care professionals in Denmark, who have a high PSM irrespective of the sector they work in. She examines the effect of economic incentives and professional norms on their behaviour and performance, and finds that when strong professional norms exist economic incentives are unimportant. Ritz (2009) examined organizational performance, notably internal efficiency, in the Swiss government, and included not only PSM, organizational commitment, and job satisfaction, but also the goal orientation of organizational units and supervisor behaviour. $\mathrm{He}$ 
finds a positive relationship between public employees' attributes of PSM, organizational commitment and job satisfaction with the internal efficiency of their organizational units. However, goal-orientation exerted more influence: the more goal-oriented an organizational unit was, the higher its internal efficiency. Likewise, employees who perceive their supervisor to engage in transformational and consideration-oriented leadership behaviour also assess the internal efficiency of their units to be higher. Discussing the implications Ritz observes that personnel policies have frequently used ineffective pay-for-performance systems and oversimplified steering instruments without recognizing their detrimental effects on public employees' motivation and performance. He calls for personnel policies that stimulate employees' commitment to the public interest.

These studies-although apparently offering avenues for public personnel policies to contribute to public service improvement-all had their limitations. One limitation had to do with the conceptualization and measurement of the key concepts: PSM and performance. Another limitation related to the nature of the data: these were mostly cross-sectional data resulting in problems of causal explanation, and self-reported data leading to the problem of common source bias. Later studies addressed one or more of these limitations. Andersen and Serritzlew (2012) examined how commitment to the public interest, one dimension of PSM, affected the behaviour of Danish physiotherapists using register data referring to actual behaviours. Their study showed that public service motivated physiotherapists served more disabled patients, who are needier but also less lucrative than other types of patients, and thereby made a bigger contribution to society. Van Loon (2015) addressed the problem of self-reported performance by examining the relationship between employees' PSM and their work unit performance as assessed by their supervisor. In addition, she operationalized performance as a multidimensional concept and showed that PSM is positively related to overall performance as well as to some dimensions-output, service outcome, resilience-but not to efficiency and responsiveness. These European studies have significantly advanced the knowledge about the relationship between PSM and performance.

\subsubsection{HRM, PSM and Employee Outcomes}

Interest in the study of PSM's contribution to employee outcomes initially concentrated on employees' job satisfaction. Steijn (2008) broadened the study of the PSM-job satisfaction relationship by integrating personenvironment fit theory. He showed that public sector employees in the Netherlands whose needs for PSM are met by their organization have greater job satisfaction than employees whose PSM needs are not met. In addition to job satisfaction, other employee outcomes such as affective commitment are studied. Mostafa et al. (2015) demonstrated that high-performance HR practices 
have a positive effect on health care and higher education employees' affective commitment which is partially mediated by their public service motivation. Gould-Williams et al. (2014) conducted a study of local government employees in Wales and found that high commitment HR practices had an indirect positive effect on employee outcomes-job satisfaction, affective commitment - via the civic duty dimension of PSM.

Steen and Rutgers (2011) argue that public sector employees may become frustrated if they perceive that their PSM is supported merely as an instrumental management approach to increase organizational performance. Their argument that PSM might have negative effects contingent on specific situational circumstances was supported by several empirical studies. Giauque et al. (2012) studied the effect of PSM on resigned satisfaction of public servants at the municipal level in Switzerland. Resigned satisfaction is a particular form of work satisfaction that reflects individuals' sense of the discrepancy between their aspirations and their actual work situation. They found that some dimensions of PSM - compassion and self-sacrifice—actually increased public servants' resigned satisfaction. Van Loon et al. (2015) studied the relationship between PSM and employee well-being, including job satisfaction as well as burnout, among employees in people-processing organizations (police, municipalities) and people-changing organizations (schools, hospitals, prisons) in the Netherlands. They find that in people-changing organizations, PSM relates to higher burnout and lower job satisfaction when the societal impact potential they perceive through their job or organization is high, whereas in people-processing organizations PSM relates to higher burnout and lower job satisfaction when the societal impact potential is low. Thus PSM may have negative effects on employee well-being but contingent on organizational and job characteristics. However, the specific mechanism suggested by Steen and Rutgers (2011) that an instrumental management approach to PSM might have adverse effects has not been confirmed yet.

\subsection{Conclusion}

The main conclusions of this review of European research of public personnel reforms and public sector HRM in Europe are summarized here.

There is a lack of recent comparative studies of public personnel reforms. However, the available evidence suggests that NPM-related ideas continue to influence public sector personnel management. There are no signs of a further decentralization of $\mathrm{HR}$ decision-making in central government across the EU Member States. Core HR practices such as salaries, working hours, and headcount reductions are subject to decision-making at central level, and management autonomy is constrained because other stakeholders such as employee representatives are involved. However, other HR practices such as performance management, training and development, and flexible working patterns have often been decentralized to local management. European 
researchers interested in the impact of the public management reforms on the public values characterizing the institutional context showed that the public service ethic can still be found, but so can manifestations of a managerialist logic and a pragmatic stance. These studies provide support for what Pollitt and Bouckaert (2011) call a Neo-Weberian State, involving a Weberian bureaucratic logic that goes along with a public servant role-identity as well as the use of management practices to deliver public service performance.

In the past few years, several studies have been conducted on the effect of leadership on organizational change and organizational performance. Overall, these studies conclude that leadership matters. That is, leadership can have a significant impact on the implementation of public management reforms and the improvement of public service performance, on the one hand through creating a supportive environment for employees and on the other hand through communicating organizational public values. The studies that we discussed in Sect. 12.3 include various moderating and mediating variables, such as core self-evaluations, job satisfaction, PSM, and organizational goal clarification. Future research can study these and other moderating and mediating variables in a systematic way, and use advanced research designs and methods to provide robust evidence for their causal impact on performance. Moreover, research showed that organizations can stimulate effective leadership by providing opportunities to participate in management/leadership development programmes. However, the learning transfer will only be achieved if the development programmes are contextualized and if managers perceive sufficient levels of discretion carrying out their managerial tasks.

While NPM-inspired reforms sought to increase public service performance through the introduction of private sector instruments such as monetary incentives and performance management, PSM research has focused on public service motivation as a resource of HRM for public service performance. Several studies have provided empirical evidence of the role personnel policies can play in achieving a public service motivated workforce, which is a resource for public organizations because public service motivated employees perform better. However, the relationship between PSM and performance is complex and contingent as recent studies have shown. Additional variables including person-job fit, person-organization fit, affective commitment, and the societal impact potential of the job partly mediate the PSM-performance relationship. Moreover, some HR practices, notably pay-for-performance systems have a crowding out effect on PSM and thereby affect performance negatively. PSM is not only positively related to performance, but also to employee outcomes such as job satisfaction. However, there is also a dark side to PSM, because dependent on specific job and organization characteristics PSM can have negative effects and cause resigned satisfaction and burnout among public employees. These results underline the importance of designing personnel policies that are aligned with both the public service and the employee outcomes that public organizations aim to achieve. In addition, European research demonstrates that among the conditions that contribute 
to public service performance, understood as a multidimensional concept, the role of managers in the implementation of personnel policies is pivotal. Supervisors' leadership behaviour has a positive effect on employees' PSM and can stimulate this resource for public service performance by providing them with opportunities to provide meaningful public service.

\section{REFERENCES}

Andersen, L. (2009). What determines the behaviour and performance of health professionals? Public service motivation, professional norms and/or economic incentives? International Review of Administrative Sciences, 75, 79-97.

Andersen, L., \& Serritzlew, S. (2012). Does public service motivation affect the behaviour of professionals? International Public Management Journal, 35, 19-29.

Andersen, L., Leisink, P., \& Vandenabeele, W. (forthcoming). Public personnel policies and HRM: Developments within the field and in EGPA's permanent study group on Public Personnel Policy. In E. Ongaro et al. (Eds.), Did EGPA make a difference to the study and practice of public administration in Europe? Brussels: Bruylant.

Bach, S., \& Bordogna, L. (2013). Reframing public service employment relations: The impact of economic crisis and the new EU economic governance. European Journal of Industrial Relations, 19, 279-294.

Bellé, N. (2013). Experimental evidence on the relationship between public service motivation and job performance. Public Administration Review, 73, 143-153.

Berg, A. (2006). Transforming public services-Transforming the public servant? International Journal of Public Sector Management, 19, 556-568.

Boyne, G., Jenkins, G., \& Poole, M. (1999). Human Resource Management in the public and private sectors: An empirical comparison. Public Administration, 77, 407-420.

Emery, Y., Giauque, D., \& Rebmann, F. (2014). The slow transformation of Swiss federal administrative elites. International Review of Administrative Sciences, 80, $687-708$.

Giauque, D., Ritz, A., Varone, F., \& Anderfuhren-Biget, S. (2012). Resigned but satisfied: The negative impact of public service motivation and red tape on work satisfaction. Public Administration, 90, 175-193.

Gould-Williams, J., Bottomley, P., Redman, T., Snape, E., Bishop, D., Limpanitgul, T., et al. (2014). Civic duty and employee outcomes: Do high commitment human resource practices and work overload matter? Public Administration, 92, 937-953.

Horton, S. (2006). New public management: Its impact on public servants's identity: An introduction to this symposium. International Journal of Public Sector Management, 19, 533-542.

Ingraham, P. (2005). Striving for balance: Reforms in Human Resource Management. In E. Ferlie, L. Lynn, \& C. Pollitt (Eds.), The Oxford handbook of public management (pp. 521-536). Oxford: Oxford University Press.

Jacobsen, C. B., \& Andersen, L. (2015). Is leadership in the eye of the beholder? A study of intended and perceived leadership practices and organizational performance. Public Administration Review, 75, 829-841.

Jacobsen, C., Hvitved, J., \& Andersen, L. (2014). Command and motivation: How the perception of external interventions relates to intrinsic motivation and public service motivation. Public Administration, 92, 790-806. 
Jeannot, G. (2006). Diffusing values or adjusting practices? A review of French public utilities. International Journal of Public Sector Management, 19, 598-608.

Kjeldsen, A. (2013). Dynamics of public service motivation: Attraction-selection and socialization on the production and regulation of social services. Public Administration Review, 74, 101-112.

Kjeldsen, A., \& Jacobsen, C. (2013). Public service motivation and employment sector: Attraction or socialization? Journal of Public Administration Research and Theory, 23, 899-926.

Knies, E., \& Leisink, P. (2014). Leadership behavior in public organizations a study of supervisory support by police and medical center middle managers. Review of Public Personnel Administration, 34, 108-127.

Leisink, P., \& Bach, S. (2014). Economic crisis and municipal public service employment: Comparing developments in seven EU member states. Transfer: European Review of Labour and Research, 20, 327-342.

Leisink, P., \& Steijn, B. (2008). Recruitment, attraction, and selection. In J. Perry \& A. Hondeghem (Eds.), Motivation in public management: The call of public service (pp. 118-135). Oxford: Oxford University Press.

Leisink, P., \& Steijn, B. (2009). Public service motivation and job performance of public sector employees in the Netherlands. International Review of Administrative Sciences, 75, 35-52.

Lodge, M., \& Hood, C. (2012). Into an age of multiple austerities? Public management and public service bargains across OECD countries. Governance: An International Journal of Policy, Administration and Institutions, 25, 79-101.

McGurk, P. (2009). Developing "middle leaders" in the public services? The realities of management and leadership development for public managers. International Journal of Public Sector Management, 22, 464-477.

McGurk, P. (2010). Outcomes of management and leadership development. Journal of Management Development, 29, 457-470.

Meyer, R., \& Hammerschmid, G. (2006). Public management reform: An identity project. Public Policy and Administration, 21, 99-115.

Meyer, R., \& Hammerschmid, G. (2010). The degree of decentralization and individual decision making in central government Human Resource Management: A European comparative perspective. Public Administration, 88, 455-478.

Meyer, R., Egger-Peitler, I., Hollerer, M., \& Hammerschmid, G. (2014). Of bureaucrats and passionate public managers: Institutional logics, executive identities, and public service motivation. Public Administration, 92, 861-885.

Mostafa, A., Gould-Williams, J., \& Bottomley, (2015). High-performance human resource practices and employee outcomes: The mediating role of public service motivation. Public Administration Review, 75, 747-757.

Perry, J., \& Wise, L. (1990). The motivational bases of public service. Public Administration Review, 50, 367-373.

Pettigrew, A. (2013). Can leaders make a difference to organisational performance? Presentation at the British Academy, 18 April.

Pollitt, C., \& Bouckaert, G. (2011). Public management reform: A comparative analysis (3rd ed.). Oxford: Oxford University Press.

Ritz, A. (2009). Public service motivation and organizational performance in Swiss federal government. International Review of Administrative Sciences, 75, 53-78.

Ritz, A., Shantz, A., Alfes, K., \& Arshoff, A. S. (2012). Who needs leaders the most? The interactive effect of leadership and core self-evaluations on commitment to change in the public sector. International Public Management Journal, 15, 160-185. 
Ritz, A., Giauque, D., Varone, F., \& Anderfuhren-Biget, S. (2014). From leadership to citizenship behavior in public organizations when values matter. Review of Public Personnel Administration, 34, 128-152.

Rondeaux, G. (2014). What are the dynamics of organizational identification in the course of modernization processes? Analysis of a Belgian administration. International Review of Administrative Sciences, 80, 110-130.

Steen, T., \& Rutgers, M. (2011). The double-edged sword. Public Management Review, 13, 343-361.

Steijn, B. (2008). Person-environment fit and public service motivation. International Public Management Journal, 11, 13-27.

Van der Voet, J., Groeneveld, S., \& Kuipers, B. S. (2014). Talking the talk or walking the walk? The leadership of planned and emergent change in a public organization. Journal of Change Management, 14, 171-191.

Van der Wal, Z., De Graaf, G., \& Lasthuizen, K. (2008). What's valued most? Similarities and differences between the organizational values of the public and private sector. Public Administration, 86, 465-482.

Van Loon, N. (2015). Is public service motivation related to overall and dimensional work-unit performance as indicated by supervisors? International Public Management Journal, 19, 78-110.

Van Loon, N., Vandenabeele, W., \& Leisink, P. (2015). On the bright and dark side of public service motivation: The relationship between PSM and employee wellbeing. Public Money \& Management, 35, 349-356.

Van Thiel, S., Steijn, B., \& Allix, M. (2007). 'New public managers' in Europe: Changes and trends. In C. Pollitt, S. Van Thiel, \& V. Homburg (Eds.), New public management in Europe (pp. 90-106). Houndmills: Palgrave.

Vandenabeele, W. (2009). The mediating effect of job satisfaction and organizational commitment on self-reported performance: More robust evidence of the PSM-performance relationship. International Review of Administrative Sciences, 75, 11-34.

Vandenabeele, W. (2014). Explaining public service motivation. The role of leadership and basic needs satisfaction. Review of Public Personnel Administration, 34, $153-173$.

Vandenabeele, W., Andersen, L. B., \& Leisink, P. (2014). Leadership in the public sector a tale of general principles and particular features. Review of Public Personnel Administration, 34, 79-83.

Vermeeren, B., Kuipers, B., \& Steijn, B. (2014). Does leadership style make a difference? Linking HRM, job satisfaction, and organizational performance. Review of Public Personnel Administration, 34, 174-195.

Vogel, D., \& Kroll, A. (2015). The stability and change of PSM-related values across time: Testing theoretical expectations across panel data. International Public Management Journal, 19, 53-77.

Waldner, C. (2012). Do public and private recruiters look for different employees? The role of public service motivation. International Public Management Journal, 35, 70-79.

Weibel, A., Rost, K., \& Osterloh, M. (2010). Pay for performance in the public sector-Benefits and (hidden) costs. Journal of Public Administration Research and Theory, 20, 387-412. 